\title{
LESSONS LEARNED FROM UTILIZING DISCRETE-EVENT SIMULATION MODELING FOR QUANTIFYING CONSTRUCTION EMISSIONS IN PRE-PLANNING PHASE
}

\author{
Changbum Ahn \\ University of Illinois at Urbana-Champaign \\ 205 N. Mathews Ave \\ Urbana, IL, 61801, USA \\ SangHyun Lee \\ University of Alberta \\ CNRL Natural Resources Engineering Facility \\ Edmonton, AB, T6G 2W2, CANADA
}

\author{
Wenjia Pan \\ University of Alberta \\ CNRL Natural Resources Engineering Facility \\ Edmonton, AB, T6G 2W2, CANADA \\ Feniosky A. Peña-Mora \\ Columbia University \\ 500 W. 120th St. New York, NY 10027, USA \\ Washington, DC 20052, USA
}

\begin{abstract}
Construction operations have a tremendous impact upon both the environment and public health due to the generation of significant amounts of airborne emissions, including greenhouse gases and other traditional criteria air pollutants. Quantifying emissions in the pre-planning phase of construction operations is the first step in identifying mitigation opportunities. The authors therefore have quantified construction emissions produced by various types of construction operations through the use of discrete-event simulation (DES). The paper focuses upon the utilization of DES in various case studies and delineates the lessons learned. An overview of each case project is provided, the benefits and limitations of DES are identified, and means to mitigate these limitations are discussed. The lessons learned from the case studies utilized in the paper are helpful; simulation practitioners and researchers can exploit these studies in simulation models that examine the environmental aspects of construction operations.
\end{abstract}

\section{INTRODUCTION}

Construction consumes large quantities of fossil fuels, such as diesel, gasoline, and natural gas, and generates significant amounts of airborne emissions that endanger both human health and public welfare (Ahn et al. 2010a). Criteria air pollutants (CAPs: $\mathrm{NO}_{\mathrm{x}}$, Particulate Matter, $\mathrm{CO}$, VOCs, Lead, and $\mathrm{SO}_{\mathrm{x}}$ ) are the airborne emissions generated by construction operations which traditionally have drawn regulatory attention; the use of diesel engines in construction produces a disproportionate level of CAP emissions compared to other types of fossil fuel engines. Construction and mining equipment account for $32 \%$ of the $\mathrm{NO}_{\mathrm{x}}$ and $37 \%$ of the Particulate Matter (PM) produced by all transportation sources, including passenger cars (EPA CAAAC 2006). Many federal and local environmental agencies have made an effort to mitigate these emissions with technological engine standards (EPA 2004), financial incentives (WCC 2009; CARB 2009), and contract requirements (CDOT 2006). One of the most proactive efforts is found in California, which requires construction projects that generate more than 85 pounds of $\mathrm{NO}_{\mathrm{x}}$ per day to reduce emissions or face a mitigation fee of $\$ 16,000$ per ton of emissions (SMAQMD 2010). Regulatory interests on greenhouse gases (GHGs) produced in construction are also growing rapidly, since they represent $1.7 \%$ of total U.S. GHG emissions and position the construction industry as the third highest industrial 


\section{Ahn, Pan, Lee and Peña-Mora}

contributor of GHGs (EPA 2008). The construction sector will need to mitigate these emissions in a carbon-constrained future.

Quantifying emissions in the pre-planning phase is a very important step; construction organizations then are able to address current and potential regulations and risks related to airborne emissions. This step can be executed by combining the predicted factors of emission sources with estimates of equipment activity in a project. In this process, discrete-event simulation (DES) is a powerful tool that can model complex construction operations (Martinez and Ioannou 1999) and be utilized to provide reliable estimates of equipment activity. The paper utilizes discrete-event simulation to quantify construction emissions in several case studies (Ahn et al. 2009; Ahn et al. 2010b; Ahn et al. 2010c). The lessons learned from these case studies are presented to provide points of reference for simulation practitioners and researchers, who can utilize the information in their simulation models for more effective environmental planning.

The article is organized as follows: first, the three basic advantages of utilizing DES in emission quantification are formulated and each advantage is analyzed in detail with reference to examples drawn from previous case studies. The challenges posed by DES with regard to effective emission quantification are then discussed and, in the conclusion, recommendations for future research are outlined.

\section{ADVANTAGES OF UTILIZING DES IN CONSTRUCTION EMISSION QUANTIFICATION}

DES is used for emission quantification in three case studies. The first case study (Case Study 1: Ahn et al. 2009) is an imaginary earthmoving operation that was presented in past DES research (Martinez 1998) and which utilized Stroboscope (Martinez and Ioannou 1999). In the second case, the methodology of the first case is applied to a real earthmoving operation in Regina, SK, Canada (Case Study 2: Ahn et al. 2010b) using Simphony instead of Stroboscope (Hajjar and AbouRizk 1999). In the third case, construction emissions, including indirect emissions from purchased electricity, from a real tunneling operation in Edmonton, AB, Canada (Case Study 3: Ahn et al. 2010c) are analyzed using COSYE (AbouRizk 2006).

As a result of examining these case studies, DES has been found to have three major advantages over the traditional approach in quantifying construction emissions at the pre-planning phase. Traditionally, construction emissions are quantified in the pre-planning phase by combining the hourly emission rate with the activity data of equipment estimated from the standard bill of quantity (Park et al. 2003; Koo and Ariaratnam 2008). Efforts to reveal airborne emissions from construction operations are mostly based on as-built activity data (Sihabuddin and Ariaratnam 2009; Cass and Mukherjee 2010). In contrast, DES provides more reliable statistical results on activity estimates for equipment. DES modeling incorporates the different resources required to execute an operation, the rules under which the different tasks that compose the operation are performed, and the stochastic nature of event and task durations. This results in more statistically reliable estimates of the operation hours for each piece of equipment. Furthermore, DES provides estimates for micro-scale equipment, generating more reliable emission estimates with the inclusion of the emission factors of micro-scale activity.

Another advantage of DES is that it allows a comparison of construction emissions from various operation scenarios with minimal effort. Once the DES model is developed, changes regarding resource use or operation setting (variables within the DES model) can be easily simulated. Minor changes in operation scenarios, which could generate large differences in results using DES modeling, are difficult to reflect in the traditional approach.

DES also offers a time-dependent pattern of emissions from a project; this permits construction managers to set control targets for emissions for each time milestone. DES models precede each time unit; estimates of emissions at each time unit therefore can be found without additional effort. DES has these three advantages over traditional planning tools and thus contains the means to aid in the planning and designing of construction operations which would have fewer emissions. 


\section{RELIABLE STATISTICAL RESULTS ON ACTIVITY ESTIMATES OF EQUIPMENT}

DES modeling does not automatically improve the reliability of activity estimates for equipment used in construction operations. However, reliable activity estimates (e.g., production rate or operation time required to perform certain work) can be obtained if the distributions of input variables are built based on properly observed data and the model is appropriately created with the representation of dynamic rules and decisions in operations; multiple runs of the DES model then can provide a statistically meaningful distribution of estimates. This greatly enhances the quality of emission estimates compared to the traditional approach that depends on the standard bill of quantity and which does not adequately incorporate the spatial and operational distinctiveness of a given project.

DES also permits a constructive utilization of micro-level emission factors. The emission rate of a piece of equipment is not constant; it varies according to vehicle activity. In the case of an excavator, for example, the emission rate when using the bucket or moving is much greater than when the vehicle is idling (Abolhasani et al. 2008). The traditional approach generally uses an average of emissions from all types of activity. An excavator that is employed in a project for a day thus is assumed to produce the same amount of emissions as any other of the same engine type, regardless of variations in activity or in the construction site. However, the duration of each vehicle activity, which determines average emission levels, is substantially influenced by both the size and mix of equipment in the fleet and the spatial characteristics of the project. DES modeling offers estimates of micro-scale vehicle activity (e.g., utilization rate), which can be combined with micro-scale emission factors. This improves the reliability of estimates in micro-level emission inventories (e.g., task level, project level), in contrast to the traditional approach, which remains efficient for macro-level emission inventories (e.g., county level, state level).

In the Case Study 2, this advantage was explored by comparing emission estimations between the two approaches. Micro-scale emission factors for the case study were found in Lewis (2009). Though the different emission factors employed in the two estimates caused substantial deviations, the utilization of micro-level emission factors within the DES model has been found to potentially have a greater impact upon the decisions of stakeholders by suggesting a different order of equipment replacement than the traditional approach.

\section{COMPARISON OF VARIOUS OPERATION SCENARIOS}

Once a DES model is created, simulations with different values for variables (e.g., the number of trucks in an earthmoving operation) are easily created; this can help stakeholders to evaluate possible operation scenarios in the pre-planning phase and then select the scenario most suitable for their purpose. The DES model is equally suitable for a comparison of construction emissions from various possible operation scenarios, allowing for the selection of the scenario with the fewest emissions. This is the main reason why stakeholders should perform emission quantification in the pre-planning phase. In addition, the DES model combined with the micro-scale emission factors could analyze the impact of minor changes in operation scenarios, which typically does not create a notable difference in emission estimation with the traditional approach.

To illustrate this advantage, various earthmoving operation scenarios in Case Study 1 were simulated to compare emissions. Among scenarios with different numbers of trucks, the scenario with seven trucks was found to generate the fewest emissions during the performance of a certain amount of work in the given conditions of the case study. The traditional approach, in contrast, generally equates more trucks with higher emissions.

\section{TIME-DEPENDENT PATTERN OF CONSTRUCTION EMISSIONS}

Construction managers are assumed to be required to control project emissions, to ensure that neither long-term nor short-term thresholds are exceeded. They therefore need to set control targets for emissions 
at time milestones determined between the start and end dates of the project. With the control target, they can evaluate their efforts to prevent emissions by comparing target and actual levels, as measured through fuel bills, sensors, etc. Determining the emission target level for a particular time milestone within the traditional approach requires vigorous effort, whereas it can be achieved effortlessly within DES. This advantage of DES has been explored in Case Study 3, wherein the time dependent patterns of energy consumption and emissions from each piece of employed equipment were identified.

The maximum impact of construction upon neighborhood air quality can also be identified within DES if the daily or hourly emission rate for operations is known. In illustration, the paper analyzes the worst case scenario in Case Study 2. Figure 1-a shows the estimated hourly $\mathrm{NO}_{\mathrm{x}}$ emissions on the second day of operation, when the largest daily $\mathrm{NO}_{\mathrm{x}}$ emissions are estimated to occur. In the first hour of the day, the emissions generated are found to make the maximum impact upon neighborhood air quality, assuming that the meteorological conditions surrounding the job site are constant. Figure 1-b shows the expected change in neighborhood $\mathrm{NO}_{\mathrm{x}}$ concentrations according to downwind distance from the job site. This result is obtained using the basic Gaussian dispersion model for the point source at the ground level (Wark et al. 1998). To simplify calculations, a certain collection of equipment is assumed to be the point source, since it was operating within a small area of less than $1 \mathrm{~km}^{2}$ (this assumption may result in a less than completely reliable dispersion model for the near neighborhood). The meteorological conditions are assumed to be class $\mathrm{D}$ for atmospheric stability, to have $1 \mathrm{~atm}$ of pressure, and to be $25^{\circ} \mathrm{C}$. Since the job site for Case Study 2 is a rural area, the equations from Brode and Wang (1992) are used to determine the coefficients of the dispersion model. Under the assumed meteorological conditions and given assumptions on dispersion modeling, $29 \mathrm{ppb}$ (parts per billion) of $\mathrm{NO}_{\mathrm{x}}$ concentration change occurs in an area up to 50 $\mathrm{km}$ away from the job site; this level of change corresponds to 29\% of National Ambient Air Quality Standards on $\mathrm{NO}_{\mathrm{x}}$ (1-hour averaging time). This preliminary analysis highlights the tremendous impact of construction operations upon the air quality of neighboring areas. An analysis of the expected maximum impact upon neighborhood air quality can be obtained through the employment of DES in quantifying construction emissions.
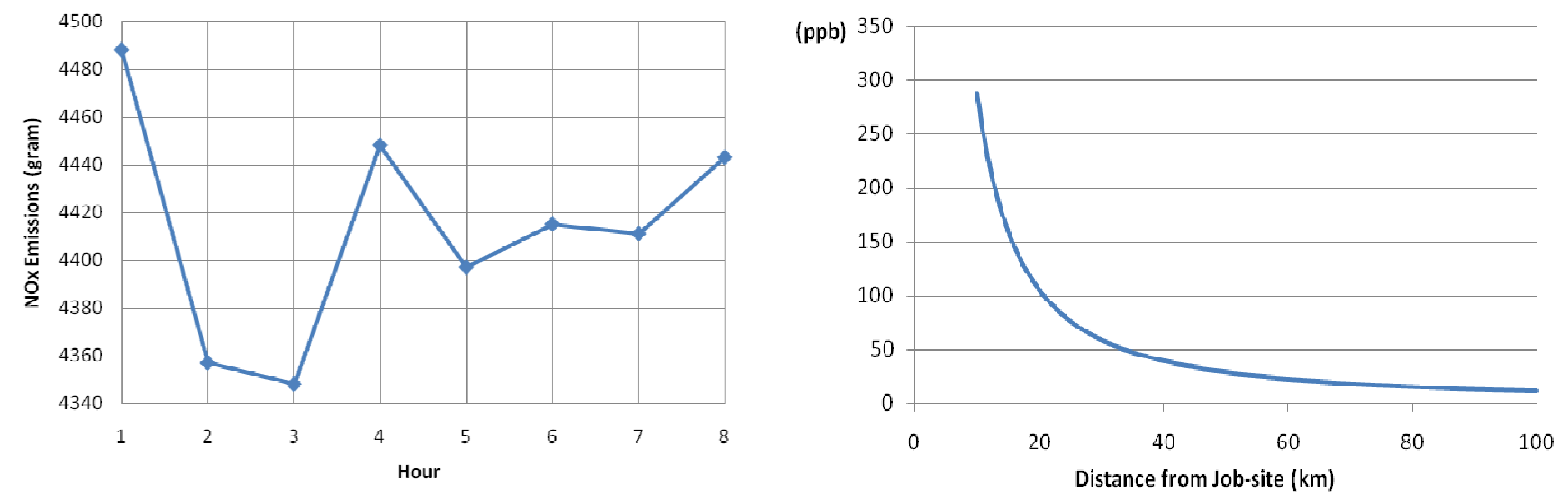

Figure 1: (a) Hourly $\mathrm{NO}_{\mathrm{x}}$ emissions of the second day in Case Study 2; (b) Expected maximum impact to $\mathrm{NO}_{\mathrm{x}}$ concentration in downwind neighborhood area in Case Study 2

\section{DISCUSSION \& CONCLUSION}

Potentially, the utilization of DES to quantify construction emissions could bring several great benefits, including the management of the environmental aspects of construction; however, many issues need to be overcome before the full advantages of DES can be obtained. The major challenge is the level of effort required to build a reliable DES model for construction operations. Martinez (2010) has described the difficulty of collecting and synthesizing the construction data necessary to build an effective model. To represent the probabilistic distribution of each input variable in the model, a number of observations on homogeneous projects which have conditions similar to the target project are required. These efforts can- 


\section{Ahn, Pan, Lee and Peña-Mora}

not be made simply for the purpose of analyzing construction emissions of a single operation. Several DES models being built for other purposes therefore need to be expanded to include an analysis dimension that can evaluate airborne emissions; this could be achieved with minimal effort. This was the primary motivation behind our decision to initiate our study with earthmoving and tunneling operations-prebuilt models for such operations already existed.

Another challenge is validation at the output level. Validation of the DES model for construction is difficult due to its unique qualities (Martinez 2010); emission estimates of the DES model is even more challenging, however, since collecting the actual output (i.e., the amount of emissions) itself needs considerable attention. It is extremely difficult to measure emissions directly from every piece of equipment employed in a construction operation. Validation using the output data from a small sample size is possible only for CAP emissions. GHG emissions can be accurately measured using fuel bills, but collecting this data in construction is not easy due to the large number of subcontractors and the preponderance of leased equipment. In addition, the development of emission factors for micro-level equipment activities is still at an early stage and estimations of micro-scale emissions using DES thus remains in development.

Our future research will focus on addressing the aforementioned challenges. With the development of DES modeling technologies in construction operations and with regard to the emission factors of microscale equipment activities, DES models for construction operations could be utilized for environmental purposes; the potential advantages of utilizing DES could greatly help stakeholders to identify construction emissions and thus avoid risks related to environmental impacts.

\section{ACKNOWLEDGEMENTS}

The authors would like to acknowledge the contribution of Dr. Julio Martinez (Purdue University) and Dr. Prasant Rekapalli to the development of Case Study 1, and the contribution of Dr. Simaan Abourizk (University of Alberta) and Hua Xie (University of Alberta) to the development of Case Study 3. This work was financially supported by the National Science Foundation Award No. CMMI-0800500, the Natural Sciences and Engineering Research Council of Canada's Discovery Grant (RGPIN 355481-08), and a Collaborative Research and Development Grant (CRDPJ 335345-05). Any opinions, findings, conclusions, or recommendations expressed in this paper are those of the authors and do not necessarily reflect the views of the National Science Foundation or the Natural Sciences and Engineering Research Council.

\section{REFERENCES}

Abolhasani, S., Frey, H. C., Kim, K., Rasdorf, W., Lewis, P. and S.H. Pang. .2008. Real-World In-Use Activity, Fuel Use, and Emissions for Nonroad Construction Vehicles: A Case Study for Excavators. Journal of the Air and Waste Management Association 58:1033-1046.

AbouRizk, S. 2006. Collaborative Simulation Framework for Multi-user Decision Support in Construction, 85321972, University of Alberta, Edmonton, AB.

Ahn, C., Rekapalli, P. V., Martinez, J. C., and F. A. Pena-Mora. 2009. Sustainability Analysis of Earthmoving operations. In Proceedings of the 4lth Conference on Winter Simulation, ed. M. D. Rossetti, R. R. Hill, B. Johansson, A. Dunkin and R. G. Ingalls. Austin, TX: Institute of Electrical and Electronics Engineers, Inc.

Ahn, C., Lee, S.H., Pena-Mora, F., and S. Abourizk. 2010a. Toward environmentally sustainable construction processes: The U.S. and Canada's perspective on energy consumption and GHG/CAP emissions. Sustainability 2(1): 354-370.

Ahn, C., Pan, W., Lee, S.H., and F. Pena-Mora. 2010b. Enhanced estimation of air emissions from construction operations based on discrete-event simulation. Proc. Int. Conf. on Computing in Civil and Building Engineering (ICCCBE) 2010, Nottingham, U.K: International Society for Computing in Civil and Building Engineering. 
Ahn, C., Xie, H., Lee, S.H., Abourizk, S., and F. A Pena-Mora. 2010c. Sustainability Analysis of Tunnel Construction Processes using Collaborative Tunneling Simulation. In Proceedings of the Construction Research Congress 2010, Banff, Alberta, Canada: the American Society of Civil Engineers.

Brode, R.W. and J. Wang. 1992. Users' Guide for the Industrial Source Complex (ISC2) Dispersion Models Volume 2. EPA-450/4-92-008b. EPA-450/4-92-008c. U.S. Environmental Protection Agency, Research Triangle Park, North Carolina.

California Air Resources Board (CARB). 2009. Carl Moyer Memorial Air Quality Standards Attainment Program. Available via <http://www.arb.ca.gov/msprog/moyer/moyer.htm> [accessed Apr,20, 2010]

California Climate Action Registry (CCAR). 2007. California Climate Action Registry General Reporting Protocol. California Climate Action Registry, Los Angeles, California.

Cass, D. and A. Mukherjee. 2010. Calculation of greenhouse gas emissions associated with highway construction projects using an integrated life cycle assessment approach. In Proceedings of the Construction Research Congress 2010, 1406-1415, Banff, Alberta, Canada: the American Society of Civil Engineers.

Connecticut Department of Transportation (CDOT). 2006. CDOT Notice to Contractors Vehicle Emissions Control. EPA, Washington, D.C. Available via <http://www.epa.gov/otaq/diesel/construction/contract-lang.htm> [accessed Apr,20, 2010]

Environmental Protection Agency (EPA). 2004. Final Regulatory Analysis: Control of Emissions from Nonroad Diesel Engines; EPA420-R-04-007; Assessment and Standards Division, Office of Transportation and Air Quality, U.S. Environmental Protection Agency, Washington, D.C.

EPA Clean Air Act Advisory Committee (CAAAC). 2006. Recommendations for Reducing Emissions from the Legacy Diesel Fleet. U.S. Environmental Protection agency, Ann Arbor, MI.

EPA. 2008. Quantifying greenhouse gas emissions in key industrial sectors. EPA 100-R-08-002, Sector Strategies Division, US EPA, Washington D.C. Available via <http://www.epa.gov/sectors/pdf/2008/2008-sector-report-508full.pdf> [accessed Apr,20, 2010]

Hajjar, D. and S. AbouRizk. 1999. Simphony: an environment for building special purpose construction simulation tools. In Proceedings of the 1999 Winter Simulation Conference, Phoenix, Ariz: Institute of Electrical and Electronics Engineers, Inc.

Kenneth, W., Warner, C. and W. Davis. 1997. Air Pollution: Its Origin and Control. $3^{\text {rd }}$ ed. New York: Addison Wesley Longman, Inc.

Koo, D. H., and S. T. Ariaratnam. 2008. Application of a Sustainability Model for Assessing Water Main Replacement Options. Journal of Construction Engineering and Management 134:563-574.

Lewis, M. P. 2009. Estimating Fuel Use and Emission Rates of Nonroad Diesel Construction Equipment Performing Representative Duty Cycles. PhD Dissertation. North Carolina State University, Raleigh, NC. Available via <http://www.ncsu.edu/theses/available/etd-03122009$183711 />$ [accessed May,20, 2009]

Martinez, J. C. 1996. STROBOSCOPE: State and resource based simulation of construction operations. $\mathrm{PhD}$ Dissertation. University of Michi http://www.lib.gan, Ann Arbor, MI.

Martinez, J. C., and P. G. Ioannou. 1999. General purpose systems for effective construction simulation. Journal of Construction Engineering and Management 125(4): 265-276.

Park, K., Y. Hwang, S. Seo and H. Seo. 2003. Quantitative assessment of environmental impacts on life cycle of highways. Journal of Construction Engineering and Management 129(1):25-31.

Sacramento Metropolitan Air Quality Management District (SMAQMD). 2010. AQMD recommended mitigation for reducing emissions from heavy-duty construction vehicles. Sacramento Metropolitan Air Quality Management District, Sacramento, California, Available via <http://www.airquality.org/ceqa/mitigation.shtml> [accessed Apr,20, 2010] 
Sihabuddin, S. S. and S. T. Ariaratnam. 2009, Methodology for estimating emissions in underground utility construction operations. Journal of Engineering, Design and Technology 7(1): 37-64.

West Coast Collaborative (WGC). 2010. Grants. Available via < http://westcoastcollaborative.org/grants.htm> [accessed Apr,20, 2010]

World Business Council for Sustainable Development and World Resources Institute (WBCSD/WRI). 2007. The greenhouse gas protocol. World Business Council for Sustainable Development and World Resources Institute, Geneva.

\section{AUTHOR BIOGRAPHIES}

CHANGBUM AHN is a Ph.D. candidate in the Construction Management and Information Technology Program at the University of Illinois at Urbana-Champaign. His research interests include planning and control strategies to minimize traditional air pollutants and greenhouse gas emissions from construction activities. His email address is <ahn3leillinois. edu>.

WENJIA PAN is a Masters student in the Department of Civil and Environmental Engineering at the University of Alberta. His research interest is exploring how to develop and apply computer-based simulation method to reliably estimate hazardous gas emissions from construction equipment. His email address is <wpan2eualberta.ca>.

SANGHYUN LEE is an Assistant Professor in the Department of Civil and Environmental Engineering at the University of Alberta. His main research interest is the understanding and management of construction dynamics through the design and development of mechanisms, models, and systems that enhance systematic understanding, effective visualization, and proactive management, particularly in mega construction projects. His email address is <sanghyuneualberta. ca $>$.

FENIOSKY PEÑA-MORA is a Dean of The Fu Foundation School of Engineering and Applied Science and Morris A. and Alma Schapiro Professor of Civil Engineering and Engineering Mechanics, Earth and Environmental Engineering, and Computer Science. His research interests include developing a sustainable construction framework for identifying and minimizing the environmental impact of construction activities. His research interests also include IT-supported collaboration frameworks for disasters as well as change management, conflict resolution, and processes integration during the design and development of large-scale civil engineering systems. His e-mail address is <fenioskyecolumbia.edu $>$ and his web address is <www. feniosky. com>. 